\title{
Basic metallosilicate catalysts from waste green container glass
}

\author{
Victoria K. Elmes, Benjamin N. Edgar, Andrew P. Mendham, Nichola J. Coleman* \\ University of Greenwich, Faculty of Engineering \& Science, Department of Pharmaceutical, Chemical \& Environmental Sciences, Chatham Maritime, Kent ME4 4TB, UK
}

\section{A R T ICLE INFO}

\section{Keywords:}

Tobermorite

Lithium metasilicate

Cancrinite

Sodalite

Catalysis

Knoevenagel condensation

\begin{abstract}
A B S T R A C T
Environmental imperatives to conserve natural resources and to divert waste streams have stimulated significant interest in mineral recycling. This study illustrates that waste green container glass cullet is a suitable feedstock material for the facile synthesis of basic metallosilicate minerals that have potential as heterogeneous catalysts for industrially significant organic reactions. The target product phases, tobermorite $\left(\mathrm{Ca}_{5} \mathrm{Si}_{6} \mathrm{O}_{16}(\mathrm{OH})_{2} \cdot 4 \mathrm{H}_{2} \mathrm{O}\right)$, lithium metasilicate $\left(\mathrm{Li}_{2} \mathrm{SiO}_{3}\right)$ and hydroxycancrinite $\left(\mathrm{Na}_{6} \mathrm{Ca}\left(\mathrm{AlSiO}_{4}\right)_{6}(\mathrm{OH})_{2} \cdot 2 \mathrm{H}_{2} \mathrm{O}\right)$ were synthesised by hydrothermal treatment of waste green cullet in alkaline media at $125^{\circ} \mathrm{C}$ for 14 days. The reaction products were characterised by powder X-ray diffraction analysis, Fourier transform infra-red spectroscopy and scanning electron microscopy. Phase-pure tobermorite (TB) was prepared from a mixture of glass and lime in sodium hydroxide solution. Impure lithium metasilicate (LS) containing minor proportions of portlandite and calcite was synthesised from the glass in lithium hydroxide solution. A mixed product of hydroxycancrinite (HC), with minor proportions of hydroxysodalite, tobermorite and hydrogarnet, was produced from the glass in a solution of aluminium and sodium hydroxides. All three glass-derived metallosilicate products were found to be effective catalysts for the Knoevenagel synthesis of ethyl ( $2 E$ )-2-cyano-3-phenylacrylate from ethyl cyanoacetate and benzaldehyde. The order of catalytic efficacy followed the trend in basicity of the metallosilicate products, LS $>$ TB $>$ HC.
\end{abstract}

\section{Introduction}

It is estimated that the total quantity of waste glass generated within the European Union in 2014 was approaching 18.5 million tonnes with an approximate recovery ratio of $79 \%$ [1]. Despite this high overall recycling rate, poor collection infrastructure and colour mismatch limit the respective supply and demand for coloured waste container glass that can be effectively recycled as new bottles and jars. For example, green and amber soda-lime-silica glasses are widely distributed as bottled alcoholic beverages; however, the viability of their recovery from the waste stream and subsequent recycling is largely restricted to regions with established wine- and beer-making industries. To address this problem, there is a number of current initiatives to 'upcycle' surplus soda-lime-silica container glass into potential value-added materials such as ceramics, geopolymers, ion-exchangers, aggregates, abrasives and fillers [2-6].
In this study, waste green container glass cullet has been evaluated as a feedstock material for the hydrothermal synthesis of basic metallosilicate mineral phases that have the potential to catalyse industrially significant organic reactions. The target product phases, lithium metasilicate $\left(\mathrm{Li}_{2} \mathrm{SiO}_{3}\right)$, tobermorite $\left(\mathrm{Ca}_{5} \mathrm{Si}_{6} \mathrm{O}_{16}(\mathrm{OH})_{2} \cdot 4 \mathrm{H}_{2} \mathrm{O}\right)$ and hydroxycancrinite $\left(\mathrm{Na}_{6} \mathrm{Ca}\left(\mathrm{AlSiO}_{4}\right)_{6}(\mathrm{OH})_{2} \cdot 2 \mathrm{H}_{2} \mathrm{O}\right)$ were synthesised by hydrothermal reaction in alkaline media at $125^{\circ} \mathrm{C}$ for 14 days. The reaction products were characterised by powder X-ray diffraction analysis (XRD), Fourier transform infra-red spectroscopy (FTIR) and scanning electron microscopy (SEM), and their potential to catalyse the Knoevenagel condensation was tested on the reaction between benzaldehyde and ethyl cyanoacetate. The ethyl (2E)-2-cyano-3-phenylacrylate condensation product was confirmed by gas chromatography with mass spectrometry (GC-MS), and the reaction rates, in the presence and absence of the metallosilicates, were monitored by gas chromatography (GC).

\footnotetext{
* Corresponding author.

Email address: n.coleman@gre.ac.uk (N.J. Coleman)
} 


\section{Materials and methods}

\subsection{Preparation and characterisation of the basic metallosilicates}

Discarded green soda-lime-silica glass wine and beer bottles were recovered from the municipal waste stream in Rochester, Kent, UK. The bottles were rinsed with water to remove the paper labels and ground to pass $125 \mu \mathrm{m}$. An oxide analysis of the green glass (Table 1) was obtained by X-ray fluorescence spectroscopy at the Materials Research Institute, Sheffield Hallam University, Sheffield, UK. All other reagents were purchased from Sigma-Aldrich, UK, and were used without further purification or modification.

Impure lithium metasilicate (LS) was hydrothermally synthesised by modifying the method described in reference 4. A mixture of $3.0 \mathrm{~g}$ of ground glass and $60 \mathrm{~cm}^{3}$ of $4 \mathrm{M} \mathrm{LiOH}_{(\mathrm{aq})}$ were heated at $125^{\circ} \mathrm{C}$ in an hermetically sealed PTFE reaction vessel under autologous pressure. Phase-pure tobermorite (TB) was produced by adapting the method reported in reference [3]. In brief, $3.5 \mathrm{~g}$ of ground glass and $1.5 \mathrm{~g}$ of calcium oxide were mixed with $60 \mathrm{~cm}^{3}$ of $4 \mathrm{M} \mathrm{NaOH}_{(\mathrm{aq})}$ and heated at $125^{\circ} \mathrm{C}$ in an hermetically sealed PTFE reaction vessel. To prepare impure hydroxycancrinite (HC), a solution containing $0.45 \mathrm{~g}$ of aluminium foil dissolved in $15 \mathrm{~cm}^{3}$ of $4 \mathrm{M} \mathrm{NaOH}_{(\mathrm{aq})}$ was contacted with $3.0 \mathrm{~g}$ of ground glass and the resulting mixture was heated at $125^{\circ} \mathrm{C}$ in an hermetically sealed PTFE reaction vessel. Each hydrothermal reaction was carried out in triplicate for 14 days and the products were then recovered by filtration, washed with deionised water to $\mathrm{pH} \sim 8$ and dried to constant mass in air at $60^{\circ} \mathrm{C}$ prior to analysis.

The reaction products were analysed by powder XRD using a Bruker D8 diffractometer with $\mathrm{Cu} \mathrm{K} \alpha=1.5406 \AA$, a step size of $0.019^{\circ}$ in the $2 \theta$ range from $5^{\circ}$ to $60^{\circ}$ and a measuring time of $1 \mathrm{~s}$ per step. FTIR spectra were acquired using a Perkin Elmer Spectrum Two spectrometer between 450 and $4000 \mathrm{~cm}^{-1}$ wavenumbers, with 10 scans at a resolution of $4 \mathrm{~cm}^{-1}$. Secondary electron images of the products were obtained from uncoated samples attached to carbon tabs on an Hitachi SU8030 scanning electron microscope with an accelerating voltage of $1 \mathrm{kV}$. The specific surface areas of the hydrothermal reaction products were obtained by nitrogen gas sorption analysis via the BET method [7].

\subsection{Catalysis of the Knoevenagel condensation reaction}

The basic catalytic properties of the hydrothermal reaction products were investigated using the Knoevenagel condensation reaction between benzaldehyde and ethyl cyanoacetate to produce ethyl (2E)-2-cyano-3-phenylacrylate (a.k.a ethyl trans- $\alpha$-cyanocinnamate) $[8,9]$. A mixture of benzaldehyde $(19.6 \mathrm{mmol})$ and ethyl cyanoacetate $(18.8 \mathrm{mmol})$ in $50 \mathrm{~cm}^{3}$ of ethanol, in a three-necked round bottom flask, fitted with a reflux condenser, thermometer and magnetic stirrer

Table 1

Oxide analysis of waste green glass.

\begin{tabular}{ll}
\hline Oxide component & Mass (\%) \\
\hline $\mathrm{SiO}_{2}$ & 72.15 \\
$\mathrm{Na}_{2} \mathrm{O}$ & 13.21 \\
$\mathrm{CaO}$ & 10.48 \\
$\mathrm{Al}_{2} \mathrm{O}_{3}$ & 1.48 \\
$\mathrm{MgO}$ & 0.94 \\
$\mathrm{~K}_{2} \mathrm{O}$ & 0.59 \\
$\mathrm{Fe}_{2} \mathrm{O}_{3}$ & 0.46 \\
$\mathrm{SO}_{3}$ & 0.28 \\
$\mathrm{Cr}_{2} \mathrm{O}_{3}$ & 0.27 \\
\hline
\end{tabular}

was heated at $80^{\circ} \mathrm{C}$ under constant stirring. At 15,60 and 105 mins, $1 \mathrm{~cm}^{3}$ aliquots of the reaction mixture were withdrawn for analysis via GC, using an Agilent 7683B instrument equipped with an HP-1 capillary column and a flame ionisation detector. The ethyl (2E)-2-cyano-3-phenylacrylate condensation product and other reaction constituents were confirmed by GC-MS (Perkin Elmer turbomass DB5 spectrometer). The same reaction was also conducted in the presence of $0.25 \mathrm{~g}$ of LS, TB or HC. All reactions were carried out in triplicate.

The relative peak area of the ethyl (2E)-2-cyano-3-phenylacrylate product in the GC chromatogram was used to represent the extent of reaction and plotted as a function of time. The relative initial rate of reaction in the presence of LS, TB or HC was taken as a representative measure of catalytic activity and was estimated from the ratio of the initial gradient of the plot in the presence and absence of the metallosilicate reaction product.

\section{Results and discussion}

\subsection{Characterisation of the lithium metasilicate product}

Lithium metasilicate is a synthetic alkaline orthorhombic inosilicate that can be prepared by solid state reaction, sol-gel synthesis, mechanical milling and hydrothermal processing [4]. Its current and prospective applications include cathodes for lithium batteries, optical waveguides, gas-sensors, $\mathrm{CO}_{2}$-storage systems and tritium breeding materials $[4,10]$. The syntheses of lithium metasilicate described in the literature have largely been carried out using analytical grade reagents such as silicic acid, colloidal silica and silicon alkoxides; although, recently, its preparation from clear waste container glass has been reported [4]. The present investigation extends that research to determine whether it is feasible to prepare lithium metasilicate from green container glass which is problematic to recycle.

The powder X-ray diffraction pattern of the lithium metasilicate product (LS) prepared in this study is shown in Fig. 1 and the identifying JCPDS files of the principal lithium metasilicate phase, and the secondary portlandite $\left(\mathrm{Ca}(\mathrm{OH})_{2}\right)$ and calcite $\left(\mathrm{CaCO}_{3}\right)$ phases present within this sample are given in Table 2. The FTIR spectrum of LS is presented in Fig. 2. Bands at 1067, 966, 864, 740 and $623 \mathrm{~cm}^{-1}$ are assigned to various vibrations of the silicate lattice, and Si-O-Li deformations give rise to the signal at $440 \mathrm{~cm}^{-1}$ [4]. In addition to the characteristic bands of lithium metasilicate, the low intensity signal at $1460 \mathrm{~cm}^{-1}$ arises from the trace calcite impurity. The characteristic sharp band at $3650 \mathrm{~cm}^{-1}$ from the non-hydrogen bonded O-H stretch-

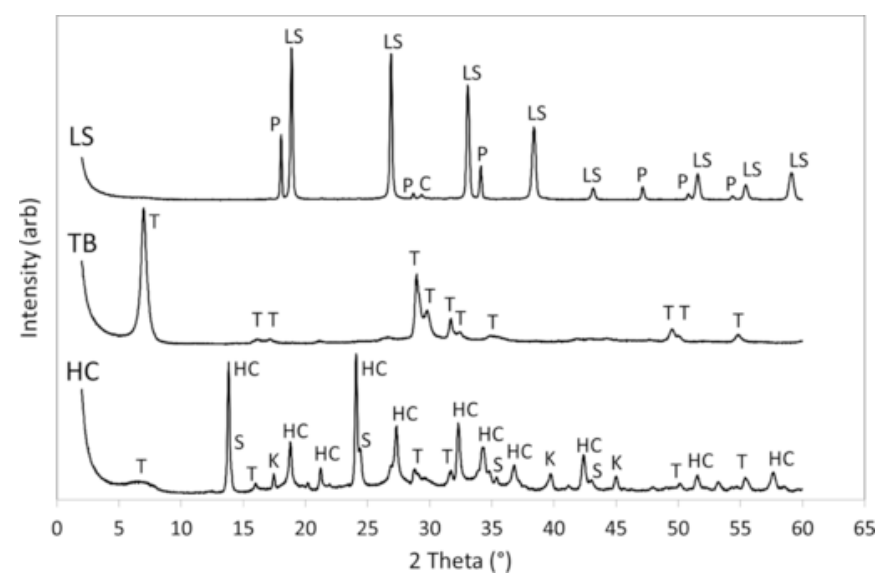

Fig. 1. Powder XRD patterns of hydrothermal products LS, TB and HC (Key: LS - lithium metasilicate, $\mathrm{P}$ - portlandite, $\mathrm{C}$ - calcite, $\mathrm{T}$ - tobermorite, $\mathrm{HC}$ - hydroxycancrinite, $\mathrm{S}$ - hydroxysodalite, $\mathrm{K}$ - katoite). 
Table 2

Properties of hydrothermal products, LS, TB and HC.

\begin{tabular}{|c|c|c|c|}
\hline Sample & LS & TB & $\mathrm{HC}$ \\
\hline $\begin{array}{l}\text { Phase (JCPDS } \\
\text { file) }\end{array}$ & $\begin{array}{l}\text { Lithium } \\
\text { metasilicate } \\
(029-0828)\end{array}$ & $\begin{array}{l}\text { Tobermorite } \\
(086-2275)\end{array}$ & $\begin{array}{l}\text { Hydroxycancrinite } \\
(046-1457)\end{array}$ \\
\hline $\begin{array}{l}\text { Phase (JCPDS } \\
\text { file) }\end{array}$ & $\begin{array}{l}\text { Portlandite } \\
\text { (44-1481) }\end{array}$ & - & $\begin{array}{l}\text { Hydroxysodalite } \\
\text { (076-1639) }\end{array}$ \\
\hline $\begin{array}{l}\text { Phase (JCPDS } \\
\text { file) }\end{array}$ & $\begin{array}{l}\text { Calcite } \\
(071-3699)\end{array}$ & - & Katoite (038-0368) \\
\hline $\begin{array}{l}\text { Phase (JCPDS } \\
\text { file) }\end{array}$ & - & - & $\begin{array}{l}\text { Tobermorite } \\
(086-2275)\end{array}$ \\
\hline $\begin{array}{l}\text { Crystallinity } \\
(\%)\end{array}$ & 77 & 51 & 46 \\
\hline $\begin{array}{l}\text { Surface area } \\
\left(\mathrm{m}^{2} \mathrm{~g}^{-1}\right)\end{array}$ & $3.75 \pm 0.15$ & $43.2 \pm 1.1$ & $6.07 \pm 0.46$ \\
\hline $\begin{array}{l}\text { Relative } \\
\text { initial rate of } \\
\text { Knoevenagel } \\
\text { reaction }\end{array}$ & $41.5 \pm 0.4$ & $24.8 \pm 0.8$ & $16.3 \pm 0.7$ \\
\hline
\end{tabular}

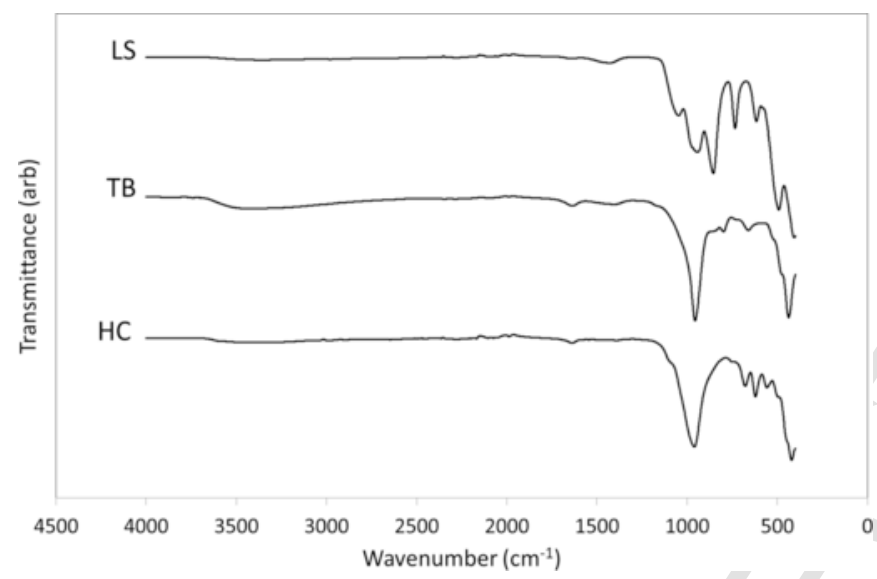

Fig. 2. FTIR spectra of hydrothermal products, LS, TB and HC.

ing vibration of portlandite is not apparent in the FTIR spectrum of sample LS indicating that this phase is not present in sufficient quantity to enable detection by this technique [4]. SEM analysis of the LS product (Fig. 3) indicates that this material comprises granules in the size range $10-60 \mu \mathrm{m}$ which are composed of nanoscale interlocking blocky crystallites. This sample was found to be approximately $77 \%$ crystalline with a BET specific surface area below $4 \mathrm{~m}^{2} \mathrm{~g}^{-1}$ (Table 2).

Analysis of sample LS demonstrates that impure lithium metasilicate can be obtained by the hydrothermal processing of green soda-lime-silica glass in $4 \mathrm{M} \mathrm{LiOH}_{(\mathrm{aq})}$ at $125^{\circ} \mathrm{C}$ with portlandite and calcite impurities arising from a stoichiometric excess of calcium present in the glass feedstock. These findings confirm those of a recent report which indicated that a mixed product of lithium metasilicate with minor proportions of portlandite, calcite, and lithium carbonate could be obtained by reaction between clear soda-lime-silica glass and $\mathrm{LiOH}_{(\mathrm{aq})}$ at $100{ }^{\circ} \mathrm{C}$ [4]. In the present study, the higher reaction temperature gave rise to smaller particle sizes of finer texture, which is to be expected for an hydrothermal system involving a nucleation and growth mechanism.

\subsection{Characterisation of the tobermorite product}

Tobermorites are naturally occurring layer-lattice hydrated calcium silicate minerals that can also be prepared synthetically from a wide range of analytical grade and waste silicate-bearing parent materials

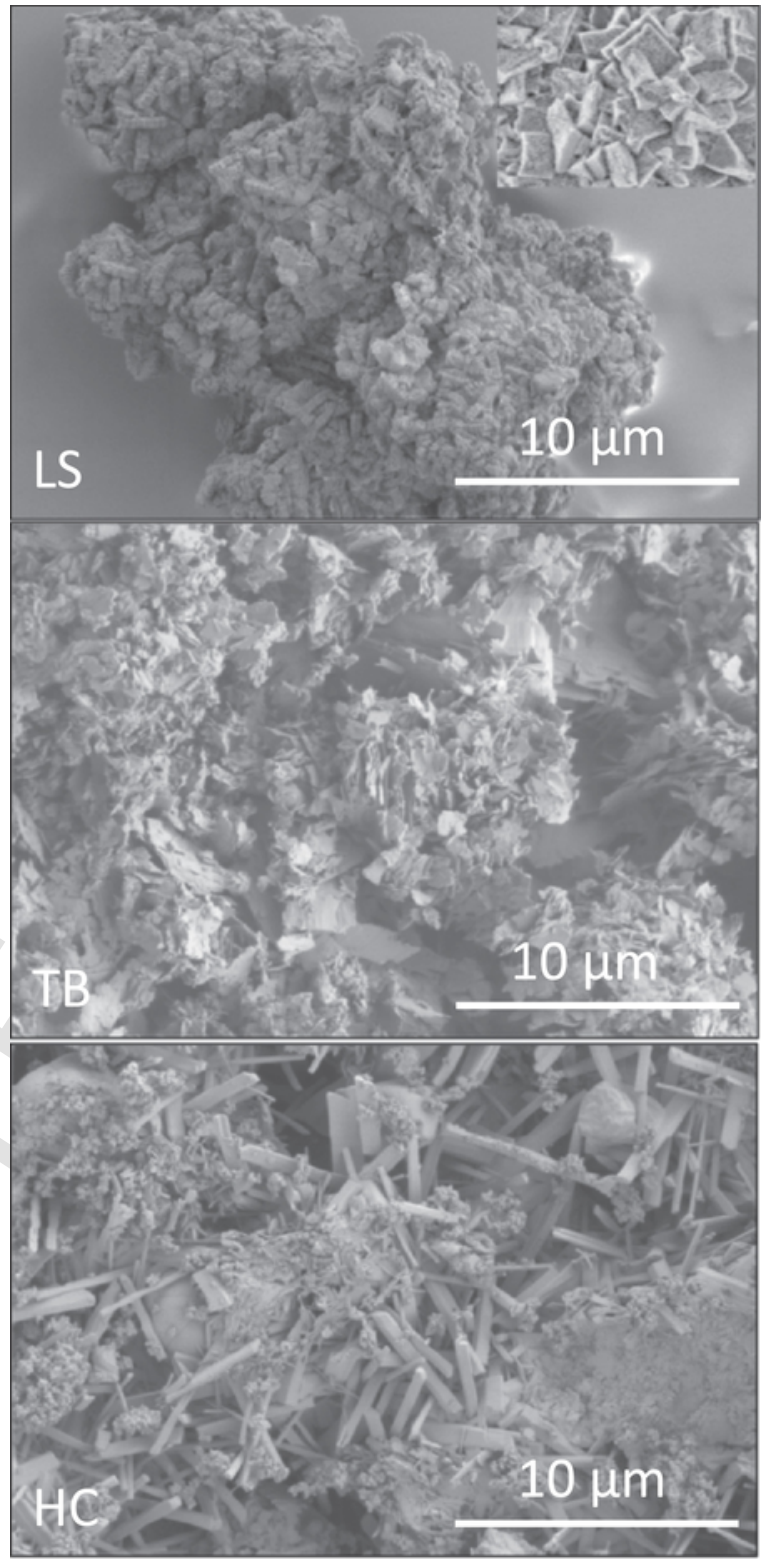

Fig. 3. Secondary electron SEM images at $\mathrm{x} 5 \mathrm{k}$ magnification of hydrothermal products, LS (with $\mathrm{x} 45 \mathrm{k}$ magnification inset), TB and HC.

under mild hydrothermal conditions [3,11-14]. The silicate lattice is compliant to substitution by other tetrahedral oxy-anions such as $\mathrm{AlO}_{4}{ }^{5-}$ and the charge-balancing inter-layer calcium ions are readily exchanged for a wide range of mono- and divalent cations [3,11-14]. $11 \AA$ tobermorite is the principal binder in autoclaved cement products and its applications in wastewater treatment, catalysis and biomedical devices are also reported [3,11-14].

The powder X-ray diffraction pattern of the tobermorite product (TB) is shown in Fig. 1 and closely resembles those of other phase-pure synthetic $11 \AA$ tobermorite samples reported in the literature $[3,11]$. Under the selected reaction conditions, the TB product was found to be $51 \%$ crystalline, which indicates incomplete conversion of the parent glass phase. The FTIR spectrum of TB is given in Fig. 2. Bands at 956 and $805 \mathrm{~cm}^{-1}$ arise from various $\mathrm{Si}-\mathrm{O}$ stretching modes and the signal at $665 \mathrm{~cm}^{-1}$ is assigned to $\mathrm{Si}-\mathrm{O}-\mathrm{Si}$ bending vibrations [12]. O-H stretching vibrations of interlayer water and silanol groups give rise to the broad signal centred around $3480 \mathrm{~cm}^{-1}$, and their bending modes are detected at $1642 \mathrm{~cm}^{-1}$. A weak signal arising from carbonate ion 
stretching at $\sim 1460 \mathrm{~cm}^{-1}$ indicates that some atmospheric carbonation has taken place (which is not uncommon during the hydrothermal synthesis of tobermorite) [11]. The TB product was found to consist of granular particles in the size range $50-250 \mu \mathrm{m}$ with the characteristic foliaceous texture of $11 \AA$ tobermorite and a specific surface area of $43 \mathrm{~m}^{2}$ $\mathrm{g}^{-1}$ (Fig. 3, Table 2).

The hydrothermal processing of a mixture of clear container glass and lime at $100^{\circ} \mathrm{C}$ in $4 \mathrm{M} \mathrm{Na}(\mathrm{OH})_{(\mathrm{aq})}$ for 7 days has been previously reported to yield a poorly crystalline $11 \AA$ tobermorite product with a surface area of $26 \mathrm{~m}^{2} \mathrm{~g}^{-1}$ [3]. This study confirms that green cullet can also be used to prepare essentially phase-pure tobermorite, and that the higher temperature $\left(125^{\circ} \mathrm{C}\right)$ and longer reaction time (14 days) give a product with significantly greater surface area which is desirable for catalytic applications.

\subsection{Characterisation of the hydroxycancrinite product}

Zeolites and feldspathoids are naturally occurring 3-D microporous aluminosilicate framework minerals that can also be synthesised in the laboratory from a wide range of aluminate and silicate precursors under alkaline hydrothermal conditions. The industrial significance of these mineral phases arises from their myriad applications in separation and adsorption technology, catalysis and engineering [15-18]. The low-silica feldspathoid 'zeotype', hydroxycancrinite $\left(\mathrm{Na}_{4}\left(\mathrm{AlSiO}_{4}\right)_{3}(\mathrm{OH}) \cdot \mathrm{H}_{2} \mathrm{O}\right)$, is readily prepared under mild hydrothermal conditions from paper sludge ash, coal combustion residue and various fly ashes [15-18]. Unlike many zeolites, hydroxycancrinite tolerates the substitution of two $\mathrm{Na}^{+}$ions for one $\mathrm{Ca}^{2+}$ ion during synthesis, so it is a popular target phase for the hydrothermal recycling of calcium-bearing aluminosilicate wastes [19].

In this study, the composition of the green glass reaction mixture was adjusted by dissolving aluminium foil in the sodium hydroxide liquor to achieve an equimolar Al:Si ratio which matches the stoichiometry of hydroxycancrinite. The powder X-ray diffraction pattern of the hydroxycancrinite product (HC) prepared by this method is shown in Fig. 1 and the identifying JCPDS files of the crystalline constituents of this sample are given in Table 2. These data confirm that the principal reaction product is hydroxycancrinite and that hydroxysodalite $\left(\mathrm{Na}_{4}(\mathrm{Al}-\right.$ $\left.\mathrm{SiO}_{4}\right)_{3}(\mathrm{OH}) \cdot \mathrm{H}_{2} \mathrm{O}$ ), poorly crystalline tobermorite and the hydrogarnet, katoite $\left(\mathrm{Ca}_{3} \mathrm{Al}_{2}\left(\mathrm{SiO}_{4}\right)(\mathrm{OH})_{8}\right)$, are also produced. The overall degree of crystallinity of $\mathrm{HC}$ was found to be $46 \%$ which indicates incomplete conversion of the parent glass under the selected reaction conditions.

The FTIR spectrum of sample HC is given in Fig. 2 and displays the characteristic vibrations associated with the aluminosilicate frameworks of the hydroxycancrinite and hydroxysodalite zeotypes $[15,20]$. The stretching and bending modes of water and hydroxyl groups present in the product phases are respectively assigned to the broad weak signals at 3480 and $1645 \mathrm{~cm}^{-1}$. Asymmetric stretches of the aluminosilicate frameworks of the zeotypes give rise to the combination band centred at $970 \mathrm{~cm}^{-1}$ which presumably obscures the lattice stretches of tobermorite. And various characteristic framework O-Si(Al)-O bending modes of the zeotypes appear as bands at 680,625 and $565 \mathrm{~cm}^{-1}$ $[15,20]$. Discrete signals arising from the vibrational modes of katoite are not apparent in the FTIR spectrum of the HC product.

Scanning electron microscopy and nitrogen gas sorption analysis revealed that the HC product is a granular material with particles in the size range $50-500 \mu \mathrm{m}$ and a BET specific surface area of $\sim 6 \mathrm{~m}^{2} \mathrm{~g}^{-1}$. The surface of the HC particles is principally composed of needle-like hexagonal hydroxycancrinite crystals interspersed with bevelled ball-like crystals of cubic hydroxysodalite (Fig. 3). Also distributed across the surface is a finer sub-micron-sized material that comprises foliaceous tobermorite and indistinct spherical aggregates of the hydrogarnet phase (Fig. 3).

Zeolites and zeotypes are thermodynamically metastable phases that form under alkaline hydrothermal conditions by a nucleation and growth mechanism [21]. Their synthesis conforms to the Ostwald Law of Successive Transformations such that a series of transient intermediate phases is formed as a function of reaction time. For example, cancrinite is known to form as a by-product of the Bayer process via the successive conversion of zeolite LTA to sodalite then cancrinite [20]. In fact, the successive solution-mediated transformation of sodalite to cancrinite has been acknowledged by many researchers and is reported to be promoted in the presence of calcium ions $[19,20]$. This accounts for the presence of both hydroxysodalite and hydroxycancrinite in the HC product in the current study, with tobermorite and hydrogarnet arising from the stoichiometric excess of calcium in the glass feedstock.

\subsection{Catalysis of the Knoevenagel condensation reaction}

The Knoevenagel reaction is widely utilised in the synthesis of fine chemicals and pharmaceuticals to form new carbon-carbon bonds $[8,9]$. This reaction generally involves the condensation of an aldehyde or ketone with an activated methylene group in solution in the presence of an organic base. The use of an homogeneous basic catalyst presents problems associated with the separation of the product from the reaction medium and generates a large volume of caustic waste liquor. In order to facilitate the recovery of the product and to minimise the management and disposal of corrosive liquid effluent, waste-derived solid bases have recently been proposed for the heterogeneous catalysis of the Knoevenagel reaction $[8,9]$.

In this study, the potential of the glass-derived lithium metasilicate, tobermorite and hydroxycancrinite products to catalyse the Knoevenagel condensation was tested on the reaction of between benzaldehyde and ethyl cyanoacetate to produce ethyl (2E)-2-cyano-3-phenylacrylate. The reaction profiles in the absence and presence of LS, TB or HC are plotted in Fig. 4 and the relative initial reaction rates are given in Table 2. These data indicate that all three basic metallosilicates significantly enhanced the rate of reaction, and that the order of their catalytic efficacy was LS > TB > HC. In each case, two additional minor phases were also detected by GC, at respective concentrations below $0.05 \%$ and $0.002 \%$, which were identified by mass spectrometry as ethyl (2Z)-2-cyano-3-phenylacrylate and benzoic acid. Ethyl (2Z)-2-cyano-3-phenylacrylate is the more sterically-hindered isomer of the principal product and benzoic acid is present as a common impurity of the benzaldehyde reagent [22]. These findings confirm those of other

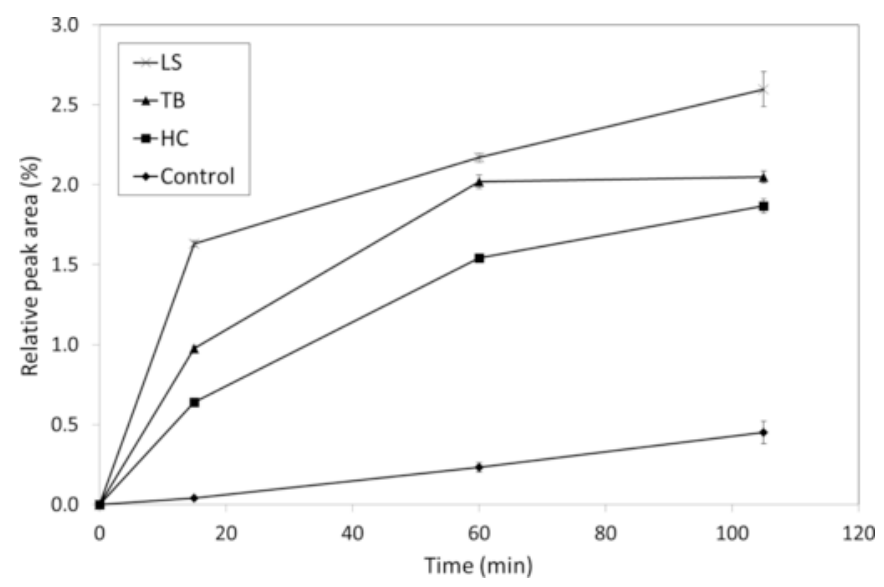

Fig. 4. Reaction profiles of ethyl (2E)-2-cyano-3-phenylacrylate in the absence and presence of LS, TB and HC. 
studies which report that basic metallosilicate catalysts are highly selective for Knoevenagel condensation reactions and that their catalytic activity derives from the abundance and strength of the basic sites presented by the material $[8,9,22,23]$.

In addition to the Knoevenagel condensation, these glass-derived materials are candidate heterogeneous catalysts for a range of other industrially significant reactions such as transesterification and biodiesel production [24]. In this respect, further work to explore the recovery and reuse potential of the glass-derived LS, TB and HC catalysts in the Knoevenagel condensation and other organic reactions is now in progress.

\subsection{Waste container glass as a potential feedstock for silicate phases}

Flint and coloured soda-lime-silica container glasses comprise $70-75$ wt $\%$ of $\mathrm{SiO}_{2}, 13-17 \mathrm{wt} \%$ of $\mathrm{Na}_{2} \mathrm{O}$ and $5-10 \mathrm{wt} \%$ of $\mathrm{CaO}$ with other binary oxide constituents, such as $\mathrm{Al}_{2} \mathrm{O}_{3}, \mathrm{MgO}$ and $\mathrm{K}_{2} \mathrm{O}$, below $5 \mathrm{wt} \%$ [25]. Trace quantities of iron and chromium are also present as impurities in flint glass which impart a faint, barely perceptible, green colour. A further combination of iron and chromium oxides is added to the melt to produce green glass and amber glass is obtained by the addition of sulphur, carbon and iron oxide. The final oxide concentrations of each additional chromophoric constituent present in finished green and amber container glass are typically below $0.5 \mathrm{wt} \%$. At these low concentrations, colour variation among different container cullet feedstocks for the synthesis of silicate minerals is unlikely to have a significant impact on the phase evolution and purity of the resulting products. In this respect, both flint and coloured container glasses are potentially valuable and versatile feedstock materials for the facile preparation of basic metallosilicate phases under mild hydrothermal conditions.

Waste container cullet is particularly suitable for the synthesis of disordered, non-stoichiometric, poorly crystalline phases, such as tobermorite. Optimum yields of tobermorite are generally achieved at $\mathrm{Ca} / \mathrm{Si}$ molar ratios between 0.80 and 0.85 , and the lattice is compliant to extensive isomorphic substitutions of both $\mathrm{Ca}$ and $\mathrm{Si}$ by the other components present in the glass $[14,26]$. Hence, the reagent composition can be readily and flexibly adjusted to produce phase-pure tobermorite under modest hydrothermal conditions using waste container glass as the principal parent phase.

It is more challenging to produce highly crystalline silicate phases, from container glass, whose structures do not tolerate the incorporation of calcium ions. During hydrothermal synthesis, excess $\mathrm{Ca}^{2+}$ ions present in the glass are inevitably precipitated as calcium hydroxide under alkaline conditions. Unrequired $\mathrm{Na}^{+}$ions from the cullet do not present the same problem, as they are more soluble and remain in the reaction liquor. Strategies to remove the calcium ions from the glass, such as acid-leaching or complexation with ligands, are not likely to be viable as these would contribute significantly to complexity and cost. Nonetheless, this research has demonstrated that waste container glass can be used to synthesise impure silicate phases whose potential applications do not rely on their complete purification prior to use.

\section{Conclusion}

This study has confirmed that waste green container glass cullet can be used as a feedstock material for the hydrothermal synthesis of basic metallosilicates that have the potential to catalyse industrially significant organic reactions. The target product phases, lithium metasilicate $\left(\mathrm{Li}_{2} \mathrm{SiO}_{3}\right)$, tobermorite $\left(\mathrm{Ca}_{5} \mathrm{Si}_{6} \mathrm{O}_{16}(\mathrm{OH})_{2} \cdot 4 \mathrm{H}_{2} \mathrm{O}\right)$ and hydroxycancrinite $\left(\mathrm{Na}_{6} \mathrm{Ca}\left(\mathrm{AlSiO}_{4}\right)_{6}(\mathrm{OH})_{2} \cdot 2 \mathrm{H}_{2} \mathrm{O}\right)$ were synthesised by hydrothermal reaction in alkaline media at $125^{\circ} \mathrm{C}$ for 14 days. Phase-pure tobermorite (TB) was prepared in sodium hydroxide solution from a mixture of glass and lime. Impure lithium metasilicate (LS) containing minor proportions of portlandite and calcite was synthesised from the glass in lithium hydroxide solution. A mixed product of hydroxycancrinite (HC), with minor proportions of hydroxysodalite, tobermorite and hydrogarnet, was produced from the glass in a solution of aluminium and sodium hydroxides. All three glass-derived metallosilicate products successfully catalysed the Knoevenagel synthesis of ethyl (2E)-2-cyano-3-phenylacrylate with high specificity. The order of catalytic efficacy, LS > TB $>\mathrm{HC}$, followed the trend in basicity of the products.

\section{Conflict of interest}

Declarations of interest: none.

\section{References}

[1] Eurostat -. Waste Statistics in Europe. 〈http://ec.europa.eu/eurostat/〉 (Accessed 5 September 2017).

[2] R.V. Silva, J. de Brito, C.Q. Lye, R.K. Dhir, The role of glass waste in the production of ceramic-based products and other applications: a review, J. Clean. Prod. 167 (2017) 346-364.

[3] N.J. Coleman, Q. Li, A. Raza, Synthesis, structure and performance of calcium silicate ion exchangers from recycled container glass, Physicochem. Probl. Miner. Process. 50 (2014) 5-16.

[4] N.J. Coleman, A.P. Hurt, A. Raza, Hydrothermal synthesis of lithium silicate $\left(\mathrm{Li}_{2} \mathrm{SiO}_{3}\right.$ ) from waste glass: a preliminary study, Physicochem. Probl. Miner. Process. 51 (2015) 685-694.

[5] N. Marinoni, V. Diella, G. Confalonieri, A. Pavese, F. Francescon, Soda-lime-silica glass/quartz particle size and firing time: their combined effect on sanitary-ware ceramic reactions and macroscopic properties, Ceram. Int. 43 (2017) 10895-10904.

[6] C. Bobirică, J.-H. Shim, J.-Y. Park, Leaching behavior of fly ash-waste glass and fly ash-slag-waste glass-based geopolymers, Ceram. Int. 44 (2018) 5886-5893.

[7] N.J. Coleman, L.L. Hench, A gel-derived mesoporous silica reference material for surface analysis by gas sorption 1 . Textural features, Ceram. Int. 26 (2000) 171-178.

[8] N.P. Tangale, S.K. Sonar, P.S. Niphadkar, P.N. Joshi, Hierarchical K/LTL zeolites: synthesis by alkali treatment, characterization and catalytic performance in Knoevenagel condensation reaction, J. Ind. Eng. Chem. 40 (2016) 128-136.

[9] D. Jain, M. Mishra, A. Rani, Synthesis and characterization of novel aminopropylated fly ash catalyst and its beneficial application in base catalysed Knoevenagel condensation reaction, Fuel Process. Technol. 95 (2012) 119-126.

[10] A. Alemi, S. Khademinia, Part I: lithium metasilicate $\left(\mathrm{Li}_{2} \mathrm{SiO}_{3}\right)$-mild condition hydrothermal synthesis, characterization, and optical properties, Int. Nano Lett. 5 (2015) 15-20.

[11] N.J. Coleman, A.H. Bishop, S.E. Booth, J.W. Nicholson, $\mathrm{Ag}^{+}$-and $\mathrm{Zn}^{2+}$-exchange kinetics and antimicrobial properties of $11 \AA$ tobermorites, J. Eur. Ceram. Soc. 29 (2009) 1109-1117.

[12] N.J. Coleman, Aspects of the in vitro bioactivity and antimicrobial properties of $\mathrm{Ag}^{+}$-and $\mathrm{Zn}^{2+}$-exchanged $11 \AA$ tobermorites, J. Mater. Sci.: Mater. Med. 20 (2009) 1347-1355.

[13] A.P. Hurt, G. Getti, N.J. Coleman, Bioactivity and biocompatibility of a chitosan-tobermorite composite membrane for guided tissue regeneration, Int. J. Biol. Macromol. 64 (2014) 11-16.

[14] S. Komarneni, D.M. Roy, New tobermorite cation exchangers, J. Mater. Sci. 20 (1985) 2930-2936.

[15] J. Yuan, J. Yang, H. Ma, C. Liu, C. Zhao, Hydrothermal synthesis of analcime and hydroxycancrinite from K-feldspar in $\mathrm{Na}_{2} \mathrm{SiO}_{3}$ solution: characterization and reaction mechanism, RSC Adv. 6 (2016) 54503-54509.

[16] C.A. Ríos, C.D. Williams, Synthesis of zeolitic materials from natural clinker: a new alternative for recycling coal combustion by-products, Fuel 87 (2008) 2482-2492.

[17] T. Wajima, K. Munakata, Material conversion from paper sludge ash in $\mathrm{NaOH}$ solution to synthesize adsorbent for removal of $\mathrm{Pb}^{2+}, \mathrm{NH}_{4}{ }^{+}$and $\mathrm{PO}_{4}{ }^{3-}$ from aqueous solution, J. Environ. Sci. 23 (2011) 718-724.

[18] N. Koshya, D.N. Singh, Fly ash zeolites for water treatment applications, J. Environ. Chem. Eng. 4 (2016) 1460-1472.

[19] B. Xu, P. Smith, C. Wingate, L. De Silva, The effect of calcium and temperature on the transformation of sodalite to cancrinite in Bayer digestion, Hydrometallurgy 105 (2010) 75-81.

[20] C.A. Ríos Reyes, C. Williams, O.M.C. Alarcón, Nucleation and growth process of sodalite and cancrinite from kaolinite-rich clay under low-temperature hydrothermal conditions, Mater. Res. 16 (2013) 424-438.

[21] C.S. Cundy, P.A. Cox, The hydrothermal synthesis of zeolites: precursors, intermediates and reaction mechanism, Microporous Mesoporous Mater. 82 (2005) 1-78.

[22] X. Zhang, E.S.M. Lai, R. Martin-Aranda, K.L. Yeung, An investigation of Knoevenagel condensation reaction in microreactors using a new zeolite catalyst, Appl. Catal. A Gen. 261 (2004) 109-118. 
[23] S. Lima, A.S. Dias, Z. Lin, P. Brandão, P. Ferreira, M. Pillinger, J. Rocha, V. Calvino-Casilda, A.A. Valente, Isomerization of D-glucose to D-fructose over metallosilicate solid bases, Appl. Catal. A: Gen. 339 (2008) 21-27.

[24] J.A. Bennett, K. Wilson, A.F. Lee, Catalytic applications of waste derived materials, J. Mater. Chem. A 4 (2016) 3617-3637.
[25] M.F. Ashby, Materials and the Environment (Eco-Informed Material Choice) 2nd ed., Butterworth-Heinemann, Oxford, 2013.

[26] N.J. Coleman, D.S. Brassington, Synthesis of Al-substituted $11 \AA$ A tobermorite from newsprint recycling residue: a feasibility study, Mater. Res. Bull. 38 (2003) 485-497. 